\title{
In vivo analysis of cadmium in battery workers versus measurements of blood, urine, and workplace air
}

\author{
J Börjesson, T Bellander, L Järup, C G Elinder, S Mattsson
}

Department of Radiation Physics, Malmö University Hospital, S-205 02 Malmö, Sweden J Börjesson $S$ Mattsson

Department of Occupational Health, Karolinska Hospital, S-171 76 Stockholm, Sweden

$\mathrm{T}$ Bellander

Centre for Study and Prevention of Cancer, Florence, Italy T Bellander

Department of Environmental Health, Box 1186, S-172 24 Sundbyberg, Sweden L Järup

Department of Renal Medicine, Huddinge University Hospital, S-141 86 Huddinge, Sweden

C G Elinder

Correspondence to: Dr Jimmy Börjesson, Department of Radiation Physics, Lund University, Malmö University Hospital, S-205 02 Malmö, Sweden.

Accepted 18 December 1996

\begin{abstract}
Objectives-To measure in vivo the cadmium concentrations in kidney cortex (kidney-Cd) and in superficial liver tissue (liver-Cd) of nickel cadmium battery workers, and to compare the results with other commonly used estimates of cadmium exposure (current concentrations of cadmium in blood (B-Cd) and urine (U-Cd)) or repeated measurements of cadmium in workplace air (CumAir-Cd). Methods-The study comprised 30 workers with a range of duration of exposure of 11-51 years. 13 subjects were currently employed, whereas the other 17 had a median period without occupational exposure of eight years before the measurements. The in vivo measurements were made with an $x$ ray fluorescence technique permitting average detection limits of 30 and $3 \mu \mathrm{g}$ cadmium per $\mathrm{g}$ tissue in kidney and liver, respectively.
\end{abstract}

Results-19 of 30 (63\%) people had kidney-Cd and 13 of 27 (48\%) had liver-Cd above the detection limits. Kidney-Cd ranged from non-detectable to $350 \mu \mathrm{g} / \mathrm{g}$ and liver-Cd from non-detectable to 80 $\mu \mathrm{g} / \mathrm{g}$. The median kidney-Cd and liver-Cd were $55 \mu \mathrm{g} / \mathrm{g}$ and $3 \mu \mathrm{g} / \mathrm{g}$, respectively. Kidney-Cd correlated significantly with B-Cd $\left(r_{s} 0.49\right)$ and U-Cd $\left(r_{s} 0.70\right)$, whereas liver-Cd correlated significantly with U-Cd ( $r_{s}$ 0.58). Neither kidney-Cd nor liver-Cd correlated with the CumAir-Cd. The prevalence of $\beta_{2}$-microglobulinurea increased with increased liver-Cd. Conclusions-Current U-Cd can be used to predict the kidney-Cd and liver-Cd measured in vivo. In vivo measurements of kidney-Cd and liver-Cd were not shown to correlate with the individual cadmium exposure estimates, obtained by integration of the cadmium concentration in workplace air. There may be several reasons for this, including uncertainties in the estimate of the individual cumulative exposures as well as in the in vivo measurements. There was a suggestion of a relation between liver-Cd and tubular proteinuria.

(Occup Environ Med 1997;54:424-431)

Keywords: cadmium; kidney; liver
Exposure to cadmium (Cd) may cause adverse health effects in humans. ${ }^{1}$ Cadmium accumulates in liver and kidneys. The kidneys are considered to be the critical organs after long term exposure. In occupational health care as well as in epidemiological studies, the degree of cadmium concentration in the kidneys (kidney-Cd) and liver (liver-Cd) is estimated indirectly, with the current cadmium concentration in blood (B-Cd) or urine (U-Cd), or the time integrated cadmium concentration in workplace air (CumAir-Cd). When a critical concentration in the kidney cortex has been reached, renal damage may evolve. In such situations, the cadmium content in the kidneys decreases and is no longer accurately reflected by the U-Cd.

The ability to measure the cadmium concentration in vivo directly in the kidney and liver is attractive. Such in vivo techniques have been developed during the past decades, with either neutron activation analysis ${ }^{2}$ or $x$ ray fluorescence. ${ }^{3}$ The $x$ ray fluorescence method has a lower detection limit except for subjects with deeply situated organs. It also gives a lower mean equivalent dose to the body than neutron activation analysis. ${ }^{4}$

The aim of the present study was to use an $x$ ray fluorescence method for the in vivo measurement of kidney-Cd and liver-Cd in a group of long term, occupationally exposed, subjects. In particular, our interest was to compare the results with measured concentrations of B-Cd, U-Cd, and CumAir-Cd.

\section{Methods}

SUBJECTS AND THEIR EXPOSURE

The people studied $(n=30)$ were a subgroup of a larger group $(n=900)$ of nickel-cadmium battery factory workers who had a duration of employment of one year or more during the years 1931 and $1992 .^{5}$ The subjects were chosen to represent workers with a wide range of past exposure to cadmium (table 1), according to the CumAir-Cd, and were not a random sample of all workers. Three participants were women. Thirteen workers were currently employed, but the other 17 had discontinued their occupational exposure between one and 31 (median eight) years before the in vivo measurements. The mean age for the 30 people was 64 (SD 7) years and the mean duration of employment of 35 (SD 13) years. Six workers of the $\mathbf{3 0}$ had tubular proteinuria.

In the production of nickel-cadmium batteries, cadmium was mainly in the form of oxide 
Table 1 Results from in vivo measurements of kidney-Cd, liver-Cd, B-Cd, $U-C d$, and $U-\beta_{2}-m$ in occupationally exposed subjects

\begin{tabular}{|c|c|c|c|c|c|c|c|c|c|c|}
\hline Subject & $\begin{array}{l}\text { Age } \\
(y)\end{array}$ & $\begin{array}{l}\Delta T 1 / \Delta T 2 \\
(y)\end{array}$ & $\begin{array}{l}\text { CumAir-Cd } \\
\left(\mu g / m^{3} \cdot y\right)\end{array}$ & $\begin{array}{l}\text { B-Cd } \\
\text { (nmolll) }\end{array}$ & $\begin{array}{l}U-C d \\
\text { (nmol/mmol } \\
\text { creatinine) }\end{array}$ & $\begin{array}{l}U-\beta_{2}-m \\
(\mu g / m m o l \\
\text { creatinine })\end{array}$ & $\begin{array}{l}\text { Kidney-Cd } \\
(S D)(\mu g / g)\end{array}$ & $\begin{array}{l}M D C \text { kidney } \\
(\mu g / g)\end{array}$ & $\begin{array}{l}\text { Liver-Cd } \\
(S D)(\mu g / g)\end{array}$ & $\begin{array}{l}M D C \text { liver } \\
(\mu g / g)\end{array}$ \\
\hline 1 & 64 & $41 / 3$ & 2400 & 70 & 6.8 & 1.9 & $355(60)^{\star}$ & 53 & $2(2)$ & 5 \\
\hline 2 & 59 & $21 / 0$ & 17800 & 25 & 4.6 & 15.6 & $181(31)^{\star}$ & 25 & $11(1)^{\star}$ & 3 \\
\hline 3 & 50 & $25 / 0$ & 3300 & 35 & 3.3 & 2.0 & $161(24)^{\star}$ & 10 & $6(1)^{\star}$ & 3 \\
\hline 4 & 63 & $15 / 4$ & 6700 & 60 & 10.4 & 12.4 & $139(26)^{\star}$ & 30 & $13(1)^{\star}$ & 3 \\
\hline 5 & 69 & $11 / 31$ & 800 & 25 & 3.4 & 130 & $128(35)^{\star}$ & 55 & $22(1)^{\star}$ & 3 \\
\hline 6 & 63 & $45 / 0$ & 4100 & 70 & 4.7 & 23.1 & $125(20)^{\star}$ & 13 & $7(1)^{\star}$ & 3 \\
\hline 7 & 61 & $42 / 0$ & 700 & 15 & 2.3 & 0.3 & $111(24)^{\star}$ & 40 & $0(1)$ & 3 \\
\hline 8 & 64 & $38 / 11$ & 2200 & 35 & 3.1 & 26.8 & $101(15)^{\star}$ & 6 & $34(1)^{\star}$ & 3 \\
\hline 9 & 63 & $51 / 0$ & 2600 & 40 & 5.2 & 16.2 & $96(28)^{\star}$ & 47 & $2(1)$ & 3 \\
\hline 10 & 66 & $31 / 1$ & 100 & 60 & 4.4 & 9.4 & $87(20)^{\star}$ & 30 & $0(1)$ & 3 \\
\hline 11 & 51 & $19 / 0$ & 2100 & 45 & 4.9 & 8.0 & $77(12)^{\star}$ & 8 & $13(1)^{\star}$ & 3 \\
\hline 12 & 63 & $46 / 0$ & 2400 & $-\dagger$ & $-\dagger$ & $-\dagger$ & $68(2)^{\star}$ & 35 & $9(1)^{\star}$ & 3 \\
\hline 13 & 74 & $43 / 10$ & 900 & 100 & 10.8 & 780 & $63(11)^{\star}$ & 13 & $83(3)^{\star}$ & 6 \\
\hline 145 & 59 & $41 / 0$ & 1000 & 40 & 4.7 & 23.6 & $61(29)^{\star}$ & 52 & $-\ddagger$ & \\
\hline 15 & 69 & $19 / 24$ & 900 & 50 & 4.6 & 3600 & $55(13)^{\star}$ & 19 & $8(1)^{\star}$ & 3 \\
\hline 16 & 69 & $13 / 7$ & 1800 & 15 & 2.1 & 6.3 & $54(11)^{\star}$ & 15 & $2(1)$ & 3 \\
\hline 17 & 63 & $44 / 0$ & 1500 & 45 & 3.2 & 8.9 & $45(8)^{\star}$ & 6 & $3(1)$ & 4 \\
\hline 18 & 66 & $48 / 1$ & 1700 & 35 & 5.8 & 268 & $34(21)$ & 44 & $13(1)^{\star}$ & 4 \\
\hline 19 & 70 & $50 / 5$ & 3700 & 30 & 1.5 & 5.1 & $30(15)^{\star}$ & 30 & $-3(1)$ & 4 \\
\hline 20 & 71 & $48 / 7$ & 1900 & 5 & 1.2 & 0.5 & $28(5)^{\star}$ & 28 & $-2(1)$ & 3 \\
\hline 21 & 72 & $41 / 7$ & 2100 & 40 & 4.0 & 1.6 & $25(24)$ & 49 & $12(1)^{\star}$ & 3 \\
\hline 22 & 52 & $26 / 0$ & 1700 & 35 & 2.4 & 5.7 & 24 (18) & 35 & $2(1)$ & 3 \\
\hline 23 & 61 & $17 / 0$ & 800 & 10 & 1.0 & 6.4 & $14(9)$ & 19 & $4(1)^{\star}$ & 3 \\
\hline 24 & 48 & $27 / 0$ & 800 & 20 & 2.9 & 6.1 & $9(7)$ & 12 & $-1(1)$ & 3 \\
\hline $25 \delta$ & 64 & $47 / 2$ & 900 & 10 & 0.8 & 4.6 & $7(6)$ & 15 & $-\ddagger$ & \\
\hline 26 & 72 & $44 / 7$ & 700 & 15 & 2.3 & 0.4 & $4(24)$ & 44 & $2(1)$ & 3 \\
\hline $27 \S$ & 60 & $38 / 0$ & 12500 & 10 & 2.3 & 8.5 & $0(6)$ & 13 & $-\ddagger$ & \\
\hline 28 & 56 & $16 / 8$ & 800 & 80 & 2.6 & 3.0 & $-3(22)$ & 47 & $-2(1)$ & 4 \\
\hline 29 & 64 & $48 / 1$ & 1600 & 5 & 0.5 & 10.6 & $-20(20)$ & 41 & $-3(1)$ & 3 \\
\hline 30 & 70 & $41 / 7$ & 1600 & 10 & 2.0 & 63.7 & $-158(98)$ & 155 & $-1(1)$ & 3 \\
\hline
\end{tabular}

* The estimated cadmium concentration exceeded the MDC.

† Data not available for this person.

$¥$ Not measured (body burden not estimated for this person).

$\oint$ Female.

$\Delta \mathrm{T} 1=$ the period of employment; $\Delta \mathrm{T} 2=$ the period of non-occupational exposure just before the measurement; MDC $=$ the minimum detectable concentration; $\mathrm{SD}$ in the kidney-Cd refers to counting statistics and the contribution from positional uncertainty $( \pm 2 \mathrm{~mm})$, but the SD for liver-Cd includes only the pulse statistics.

and hydroxide. Exposure to airborne dust containing these compounds, may have occurred in a large part of the production factories. Also, exposure may have occurred from cadmium contaminated cigarettes and food. Before 1946 , there were no quantitative data on work conditions, but eye witnesses describe them as very dusty. ${ }^{6}$ Cadmium in workplace air has been measured sporadically since 1946 , and systematically since 1972 . Based on a previous collection of these data, ${ }^{6}$ the average exposure for all workers has been roughly estimated to be $1 \mathrm{mg} / \mathrm{m}^{3}$ before $1947,300 \mu \mathrm{g} / \mathrm{m}^{3}$ in $1947-63$, $50 \mu \mathrm{g} / \mathrm{m}^{3}$ in $1964-74$, and $20 \mu \mathrm{g} / \mathrm{m}^{3}$ thereafter. ${ }^{7}$ Knowing the subject's work periods, his or her individual CumAir-Cd was roughly estimated. There may be substantial differences between workers in external exposure even if our estimates indicate the same cadmium exposure level. Also, there are certainly important differences between people in uptake of cadmium, related to smoking habits, personal hygiene, work load, and the use of personal protective equipment.

However, recently it has been possible to perform a more detailed historical exposure analysis, accounting for major differences not only between periods, but also between jobs. Historical information on the development of production, work practices, and preventive measures, was collected by means of interviews and data on protocol, and the exposure estimates (three levels) were based on all available data (Bellander et al, unpublished data). This updated information on CumAir-Cd was used in the present paper. A similar construction of a cumulative B-Cd index over a worker's work period was impossible due to lack of B-Cd measurements for long periods.

BLOOD AND URINE SAMPLES

With atomic absorption spectrophotometry blood samples and urine samples were analysed for cadmium: urine samples were also analysed for $\beta_{2}$-microglobulin $\left(\mathrm{U}-\beta_{2}-\mathrm{m}\right)$ with a radioimmunoassay technique. ${ }^{5}$ The $\mathrm{B}-\mathrm{Cd}$ analyses were made by an external laboratory. To prevent the degradation of $\mathrm{U}-\beta_{2}-\mathrm{m}$ occurring in acidic urine each worker had $4 \mathrm{~g}$ of sodium bicarbonate dissolved in water the night before the morning urine was collected for protein analyses.

A cut off value of $25 \mu \mathrm{g} / \mathrm{mmol}$ creatinine for the excretion of $U-\beta_{2}-m$ was chosen. This value corresponds to the 90th percentile in a United States reference population. ${ }^{5}$ Most likely the cut off level in a general population is higher than an industrially exposed group of workers as a healthy worker effect may be present in industry. Recent studies of workers exposed to mercury and controls have thus shown 95 percentiles for $\mathrm{U}-\beta_{2}-\mathrm{m}$ as low as $17-18 \mu \mathrm{g} / \mathrm{mM} .^{58}$

IN VIVO MEASUREMENTS OF CADMIUM IN KIDNEY AND LIVER

The original technique for in vivo measurement of cadmium with $x$ ray fluorescence $^{9}$ has been improved during the past 20 years by the use of partly plane polarised photons, a variable detector collimator, and a silicon detector. ${ }^{10-12}$ The method is based on excitation of cadmium atoms by photons from modified $x$ ray therapy equipment. 
The minimum detectable concentration (MDC) is analogous to the definition of the minimum detectable amount of low level radioactivity defined in the International Commission on Radiological Units and Measurement (ICRU). ${ }^{13}$

$$
\mathrm{MDC}=3 \times\left(\mathrm{N}_{\mathrm{Bg}}\right)^{1 / 2} \times\left(\mathrm{C} / \mathrm{N}_{\text {net }}\right)[\mu \mathrm{g} / \mathrm{g}]
$$

where $\mathrm{N}_{\mathrm{Bg}}$ denotes the number of background counts under the characteristic cadmium $x$ rays, $\mathrm{N}_{\text {net }}$ the net counts in the cadmium peaks, and $\mathrm{C}$ the cadmium concentration. Rearranging this equation shows that when the cadmium concentration $\mathrm{C}$ is equal to MDC the $N_{\text {net }}$ is equal to three times the SD in the number of background counts $\left(\mathrm{N}_{\mathrm{Bg}}\right)$. As the $\mathrm{C}$ and $\mathrm{N}_{\text {net }}$ are directly proportional to each other the MDC cannot take on a negative value. However, at low cadmium concentrations and large background values the mathematical analysis of the measured pulse height distribution (see later) can result in negative $N_{\text {net }}$ values. This will result in a concentration $C$ below zero. Thus, as a result a negative cadmium concentration in a kidney or liver may be reported although the MDC is above zero.

The sensitivity decreases and, accordingly, the MDC increases rapidly with larger organ depths due to a decreased detector solid angle and an increased photon attenuation. The MDC is about 3,11 , and $34 \mu \mathrm{g} / \mathrm{g}$ for depths to the kidney surface of 30,50 , and $70 \mathrm{~mm}$, respectively. The depth dependence also implies that the measurement is strongly depth selective - that is, the cadmium concentration in the right kidney is determined essentially within a depth of about $15 \mathrm{~mm}$ from the kidney surface. Thus, cadmium is almost exclusively measured in the kidney cortex. ${ }^{10}$ There is no interference from liver-Cd when kidney-Cd is measured.

Before the in vivo measurement, the kidney position and the depth to the kidney surface from the back were measured with linear array ultrasound (Philips Sono Diagnost, 2.2 MHz B-Scan) with the subject sitting in the measurement position. The kidney position was also verified at the end of the in vivo measurement. The individual difference in the kidney depth at the ultrasound measurements before and after the in vivo measurement was 1-3 mm.

Repeated measurements of the kidney depth without subject movements between measurements imply a smaller variation $( \pm 1 \mathrm{~mm}, S D){ }^{4}$ This figure is consistent with the intrinsic uncertainty of the ultrasound equipment. However, when repeated measurements of the kidney, including subject movements between measurements, were made in one subject a 2-3 $\mathrm{mm}$ (SD) variation in the kidney depth was found. Thus, the higher figures $(2-3 \mathrm{~mm})$ are a combination of the uncertainty of the ultrasound equipment, the natural movement of the kidney position at respiration and expiration (see later), as well as the movement of the human body as a whole. Furthermore, the variation of the positions of the two points on the subject's back and his or her kidney surface that are used for the depth measurement, is added. A figure of $2-3 \mathrm{~mm}$ variation is in agreement with earlier published data. ${ }^{9}$

The position of the liver was assessed similarly, and the measurement position was taken to be the periphery of the liver volume. As the liver is a large organ and has a more homogenous cadmium concentration than the kidney, ${ }^{14}{ }^{15}$ the position is not supposed to be as critical as for the kidney.

Measurements were made in the right kidney due to the assumption of its lower mobility, during respiration, compared with the left kidney. However, a study of kidney mobility shows that the two kidneys have about equal mobility (2-3 $\mathrm{mm})$ during both inspiration and expiration. ${ }^{16}$ Thus, the choice of left or right kidney should not be made from this standpoint. Instead, as the photon attenuation is not equal for different human tissues-for example, soft tissue, fat, and bone-the kidney least "hidden" behind ribs and which has the smallest depth is the one to measure (see later).

The kidney-Cd and liver-Cd were calculated by calibrations made from each subject's in vivo measurement. Calibrations used a sealed plastic model containing cadmium dissolved in water. These models were placed in a water filled model of a body trunk in positions corresponding to the in vivo measured positions of the kidney and liver.

We corrected for the fact that the in vivo measurements were made in tissues which are not water equivalent. Under the assumption that the ratio between the number of net counts and background counts would be the same at both calibration and in vivo measurement, the number of net pulses at the calibration was corrected by the ratio of the number of background counts registered at the in vivo to the calibration measurements. This means that the number of net counts at the calibration was decreased if bone was present at the in vivo measurement and increased if fat was present. The validity of the correction factor was tested by putting either an air cavity or a bone equivalent model in the path between the front of the detector collimator and the kidney model. Results showed that the correction partly decreased, but did not totally eliminate, the influence of inhomogeneity. We also tested the use of the ratio of the broad incoherent scatter peak areas in the measured pulse height distributions. However, this correction procedure was inferior to the other.

The analysis of the registered pulse height distribution used a non-linear regression technique, included in a commercially available statistical program package. ${ }^{17}$ The model fitted to the experimental data comprised a second degree polynomial background and two Gaussian peaks. These represented the cadmium $\mathrm{K}_{\mathrm{a}}$ peaks. The tail at the low energy side of the full energy peak was modelled by an exponential function. ${ }^{18} 19$ The position of the Gaussian peak could vary within narrow energy limits, whereas the ratio between the net counts of the $K_{\alpha}$ peaks was fixed. The estimated sum of the peak areas was converted to a cadmium concentration. 
As the non-linear regression technique had not been applied to our analysis of cadmium pulse height distributions before, we compared it with two other algorithms used earlier. ${ }^{10} 20$ There was no significant difference (Student's $t$ test) between the mean number of net counts of the three algorithms when these were applied to 20 pulse height distributions from calibration measurements $(40 \mu \mathrm{g} / \mathrm{g}$ cadmium model immersed in water). The observed variation in the number of net pulses recorded was similar and somewhat higher for all algorithms compared with the theoretically expected value, considering the number of net, total, and background counts. When the three algorithms were applied to pulse height distributions, obtained from measurements on a cadmium free model (blank), the $95 \%$ confidence interval $(95 \% \mathrm{CI})$ of the mean number of net counts, for all methods, included zero. These results do not indicate a large advantage of using the complex regression technique; however, further improvements of the technique may be possible.

The in vitro accuracy of the $x$ ray fluorescence method has earlier been checked by comparative atomic absorption spectrophotometry measurements. ${ }^{11}$ The test of the in vivo precision for the present set up with a silicon detector and improved electronics was done by carrying out 10 repeated measurements in a smoker. She had a short break between each measurement during which she stood up and walked about for a few minutes, then a new kidney position measurement was made. The estimated, mean (SD) kidney-Cd was 28 (9) $\mu \mathrm{g} / \mathrm{g}$. The uncertainty in the repeated in vivo measurements, due to counting statistics, was estimated to be $7 \%$, which means that the main contribution to the total coefficient of variation of $30 \%$ came from the uncertainty in the positioning of the measurement volume and from non-uniform cadmium concentration within the cortex volume. This implies that the position uncertainty is prominent. The $30 \%$ figure is consistent with $\pm 3 \mathrm{~mm}$ displacement of the kidney position, which gives an uncertainty in the measured kidney-Cd of $\pm 25 \%$, irrespective of the measurement depth and the cadmium concentration. Thus, this figure combines with the pulse statistics to the observed coefficient of variation of $30 \%$. For comparison, the $\pm 25 \%$ figure would be $\pm 15 \%$ and $\pm 8 \%$ for $\mathrm{a} \pm 2 \mathrm{~mm}$ and $\pm 1 \mathrm{~mm}$ displacement, respectively. The coefficient of variation for liver-Cd, due to counting statistics only was estimated to be $26 \%$ and $3 \%$ at liver-Cd concentrations of 5 and $50 \mu \mathrm{g} / \mathrm{g}$, respectively.

The uncertainty figures for the kidney-Cd were calculated (square root of the sum of quadratic terms) from the uncertainties in the pulse statistics with the error from a $\pm 2 \mathrm{~mm}$ displacement (table 1). As the liver is a large organ and is thought to have a uniform cadmium concentration, a displacement of the volume intended to be studied is replaced by another part of the liver; thus, a correction was not made in this case.

From kidney-Cd measurement, the mean absorbed dose to the kidney was about 0.7
mGy and the energy imparted $0.2 \mathrm{~mJ} .{ }^{1021}$ The absorbed dose to the irradiated skin was $7 \mathrm{mGy}$ and the mean absorbed dose to the whole body (energy imparted $/ 70 \mathrm{~kg}$ ) was $3 \mu \mathrm{Gy}$. From the liver-Cd measurement, the absorbed dose in the measured volume was estimated to be 3 $\mathrm{mGy}$.

\section{STATISTICAL ANALYSIS}

The B-Cd, U-Cd, kidney-Cd, and liver-Cd were not normally distributed, thus, nonparametric tests (Spearman rank correlation coefficient, $r_{s}$ ) were used. All $P$ values were two tailed and $P$ values $<0.05$ were considered to be significant. Stepwise multiple linear regression was performed to find the predictors for B-Cd and U-Cd. The covariates included kidney-Cd, liver-Cd, and CumAir-Cd. In the regression analysis, variables which were not normally distributed were $\log$ transformed.

\section{Results}

Table 1 shows the liver-Cd, kidney-Cd, B-Cd, and U-Cd. Values for liver-Cd and kidney-Cd below the MDC, and even below zero, are presented in the tables and figures. Negative concentrations result from fitting of pulse height distributions to the inevitable statistical variation in the number of pulses. Negative values have no significance from a biological point of view, but give the reader an honest impression of the measurement accuracy and are necessary to perform accurate calculations of various means. ${ }^{22}$

The kidney-Cd exceeded the individual $\mathrm{MDC}$ in 19 of 30 cases and liver-Cd in 13 of 27 cases. The median kidney-Cd and liver-Cd were $55 \mu \mathrm{g} / \mathrm{g}$ and $3 \mu \mathrm{g} / \mathrm{g}$, respectively. Due to the large individual variation in the MDC for kidney-Cd, a weighted (weight: the inverse of individual kidney-Cd variance) mean was calculated for the whole group. The weighted mean was $73 \mu \mathrm{g} / \mathrm{g}$. The distribution of liver MDC values was less wide (3-6 $\mu \mathrm{g} / \mathrm{g})$, compared with kidney MDC values (6-155 $\mu \mathrm{g} / \mathrm{g}$ ), due to the greater similarity in measured depths for liver-Cd of all subjects. The distributions of $\mathrm{U}-\beta_{2}-\mathrm{m}, \mathrm{B}-\mathrm{Cd}, \mathrm{U}-\mathrm{Cd}$, kidney$\mathrm{Cd}$, liver-Cd, and CumAir-Cd were not significantly different between active and retired workers. Thus, active and retired workers were treated as one group.

In the following analyses, subjects with $\beta_{2}$-microglobulinuria (excretion $>25 \mu \mathrm{g} / \mathrm{mmol}$ creatinine) were treated separately. There were significant correlations between the U-Cd and kidney-Cd $\left(r_{s}\right.$ 0.70, $\mathrm{P}<0.001$, fig 1), and between the B-Cd and kidney-Cd $(r, 0.49$, $\mathrm{P}=0.019$, fig 2). The U-Cd correlated with liver-Cd $\left(r_{s} 0.58, \mathrm{P}=0.007\right)$, whereas there was no association between current $\mathrm{B}-\mathrm{Cd}$ and liver-Cd. The correlation coefficient between the kidney-Cd and liver-Cd was $r_{s} \quad 0.43$ $(P=0.06$, fig 3$)$. The weighted (weight: the inverse of the individual ratio variance) mean ratio of the kidney-Cd to liver-Cd was 7 . Linear regression analyses showed that the kidney-Cd explained $44 \%$ and $39 \%$ (multiple $r^{2}$ ) of the observed variance in the $\mathrm{U}-\mathrm{Cd}$ and $\mathrm{B}-\mathrm{Cd}$, 


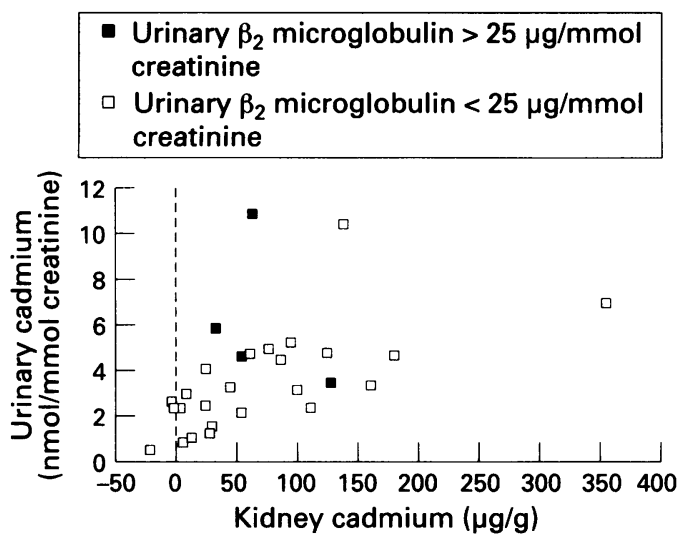

Figure 1 Cadmium concentration in urine (U-Cd) plotted against kidney cadmium concentration (kidney-Cd).

- Urinary $\beta_{2}$ microglobulin $>25 \mu \mathrm{g} / \mathrm{mmol}$ creatinine

口 Urinary $\beta_{2}$ microglobulin $<25 \mu \mathrm{g} / \mathrm{mmol}$ creatinine

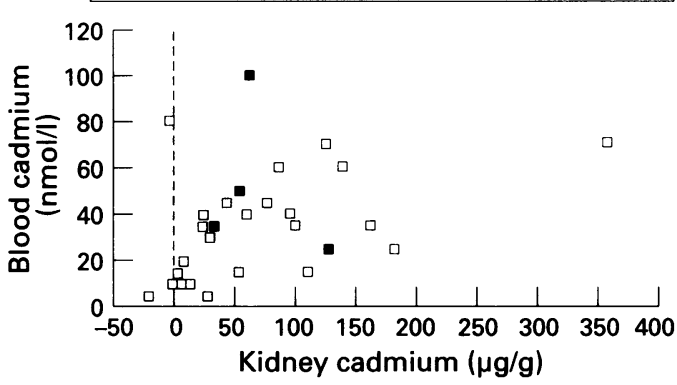

Figure 2 Cadmium concentration in blood (B-Cd) plotted against the kidney cadmium concentration (kidney-Cd).

- Urinary $\beta_{2}$ microglobulin $>25 \mu \mathrm{g} / \mathrm{mmol}$ creatinine

口 Urinary $\beta_{2}$ microglobulin $<25 \mu \mathrm{g} / \mathrm{mmol}$ creatinine

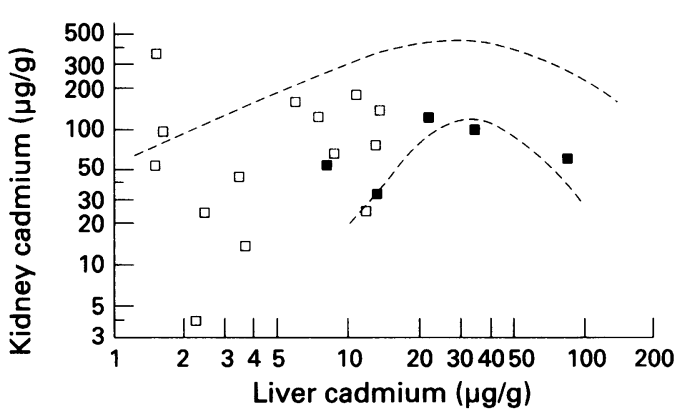

Figure 3 Kidney cadmium concentration (kidney-Cd) plotted against liver cadmium concentration (iver-Cd). The region between the curves (broken lines) shows the distribution of data points collected from other in vivo studies. ${ }^{22} 28030$ In studies where the cadmium content in the kidney was given, the content has been transformed into a cadmium concentration in the kidney cortex assuming a kidney weight of $155 \mathrm{~g}$ and a ratio of cadmium concentrations in cortex to the whole kidney of 1.25.

respectively. The liver-Cd and CumAir-Cd were not significant covariates.

The correlation between B-Cd and U-Cd was strong $(r s=0.81, \mathrm{P}<0.001)$. There was no correlation between the B-Cd, U-Cd, kidney$\mathrm{Cd}$, or liver-Cd on one hand, and the duration of employment or CumAir-Cd on the other.

When the group was divided by means of the $U-\beta_{2}-m$ cut off level, the liver-Cd distributions were significantly different $(\mathrm{P}=0.01)$, whereas this was not the case for kidney-Cd, B-Cd, or

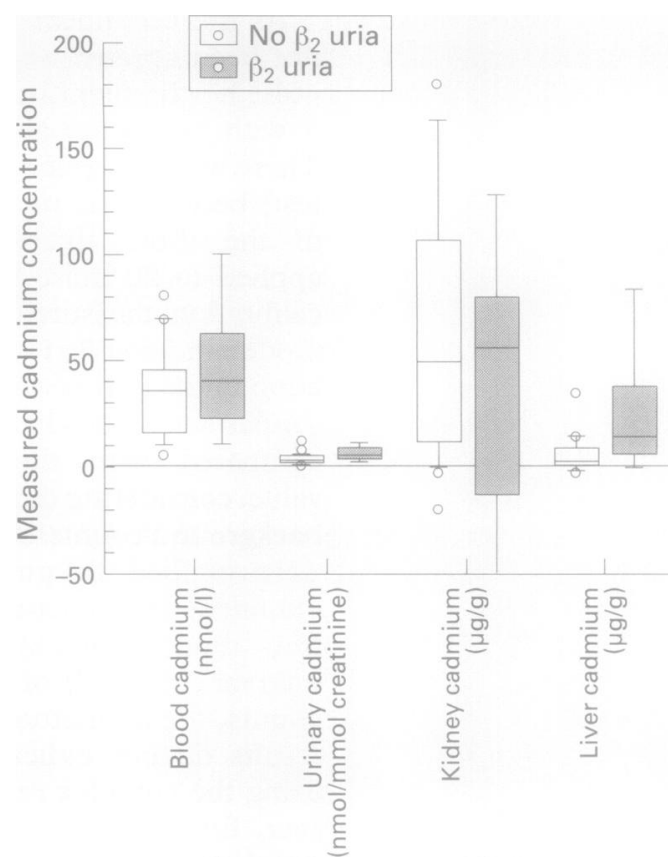

Figure 4 Box plots of $B-C d, U-C d$, kidney-Cd, and liver-Cd for the two groups of workers with increased and normal excretion of urinary $\beta_{2}$-microglobulin. Note that one subject's kidney-Cd value $(355 \mu \mathrm{g} / \mathrm{g})$ cannot be shown in the plot.

U-Cd (fig 4). Although few people were investigated in this study, a relation was indicated between liver-Cd, and response, expressed as increased excretion of $U-\beta_{2}-m$ (table 2). No similar relation was found between kidney-Cd and response (table 2). Published data ${ }^{2324}$ of the kidney (one kidney; $155 \mathrm{~g}$ ) and liver (1800 g) weights and their fraction of the body burden of cadmium (BB-Cd) were used to estimate the BB-Cd. The weighted (weight: the inverse of the individual $\mathrm{BB}-\mathrm{Cd}$ variance) mean BB-Cd, estimated from the kidney-Cd and liver-Cd data separately, was $34 \mathrm{mg}$ and 73 mg, respectively. When the estimation was made with the combined information of kidney-Cd and liver-Cd data, the weighted mean BB-Cd was $50 \mathrm{mg}$. A minimum detectable BB-Cd of $21 \mathrm{mg}$ was estimated from the median $\mathrm{MDC}$ values of kidney-Cd and liver-Cd. Correlations between the BB-Cd and $\mathrm{B}-\mathrm{Cd}(r s=0.45, \mathrm{P}=0.044)$ or $\mathrm{U}-\mathrm{Cd}(r s=0.78$, $P<0.001)$ were noted.

\section{Discussion}

Previous studies have shown that $x$ ray fluorescence can be used to measure kidney-Cd in occupationally exposed subjects, as well as in

Table 2 Prevalence of $\beta_{2}$-microglobulinuria ( $>25 \mu \mathrm{g} \mathrm{per}$ mmole creatinine) in relation to the estimated liver-Cd and kidney-Cd

\begin{tabular}{lll}
\hline & $\begin{array}{l}\text { Cases with } \\
\beta_{2} \text {-microglobulinuria } \\
n(\%)\end{array}$ & $\begin{array}{l}\text { Total number } \\
\text { of cases }\end{array}$ \\
\hline Liver-Cd $(\mu \mathrm{g} / \mathrm{g}):$ & & \\
$<5$ & $1(6)$ & 15 \\
$5-10$ & $1(25)$ & 4 \\
$>10$ & $4(50)$ & 8 \\
Kidney-Cd $(\mu \mathrm{g} / \mathrm{g}):$ & & 13 \\
$<50$ & $1(8)$ & 8 \\
$50-100$ & $2(25)$ & 5 \\
$100-150$ & $2(40)$ & 3 \\
$>150$ & $0(0)$ & \\
\hline
\end{tabular}


the general population. ${ }^{11}{ }^{25}$ In the present study, we report for the first time the measurement of liver-Cd by $x$ ray fluorescence.

The measurement of cadmium in the superficial liver tissue is favoured by a detection limit which is an order of magnitude lower than in measurement of the kidney-Cd. It is of interest to compare the presented kidney-Cd and liver-Cd with the respective detection limits for the two organs. Half of the workers in this study had liver-Cd above the MDC, whereas two thirds had kidney-Cd above the individual MDC. Furthermore, it is easier to find the liver and to keep the error in the measurement of position low. Also, the liver is less deeply situated than the kidney and the liver-Cd seems to be more uniform than the kidney-Cd. So, measurement of liver-Cd is preferable. For occupationally exposed people, liver-Cd can be high even when kidney-Cd is low. This may be due to induced kidney dysfunction. To estimate the cadmium body burden, liver-Cd may therefore be a better index than kidney-Cd. On the other hand, kidney-Cd is generally higher than liver-Cd, and from a toxicological point of view, the kidney is the critical organ. In summary, if the person's exposure history is unknown, measurements should be carried out in both kidney and liver.

Our results for kidney-Cd are in accordance with data from $x$ ray fluorescence $e^{9-11}$ and neutron activation analysis ${ }^{26-36}$ in previous studies of occupationally exposed subjects. Unfortunately, the numerical results from studies with $x$ ray fluorescence and neutron activation analysis cannot be directly compared. As the neutron activation analysis technique measures the total content of kidney- $\mathrm{Cd}$, a conversion to a cadmium concentration in the cortex must be made. The conversion includes assumptions about the kidney weight and the relation between the mean concentration of kidney-Cd and the concentration in the cortex. The between subject variation in the average weight of a kidney can be considerable (SD $42 \mathrm{~g}$, range $94-245 \mathrm{~g}$ ). ${ }^{37}$ There is also a variation of the relative volumes of medulla, cortex, and the whole kidney, whereas the conversion factor between the mean concentration of kidney-Cd and the mean cadmium concentration in the cortex seems to be similar (about 1.2-1.3) for most people.

The range of the liver-Cd is in agreement with or somewhat less than that found in neutron activation analysis studies. ${ }^{27-35} 38$ The decrease in liver-Cd is supposed to be characterised by a faster half life (about five years), ${ }^{32}$ compared with the kidney-Cd half life (about 10-30 years) as estimated from longitudinal studies of the decrease of B-Cd in retired workers. ${ }^{39}{ }^{40}$ Thus, the subjects' liver-Cd values in the present study may have been higher earlier but due to retirement and decreasing exposures over the years, they may have decreased.

The data in the present study describe a non-linear relation between kidney-Cd and liver-Cd, also seen in other in vivo studies, ${ }^{27} 28303435$ which included people with normal kidney function as well as subjects with kidney damage. The kidney-Cd seems to increase linearly with liver-Cd up to a concentration at which the liver-Cd is about 20-30 $\mu \mathrm{g} / \mathrm{g}$, after which kidney-Cd decreases due to kidney dysfunction. Accordingly, liver-Cd has been proposed as a more reliable indicator of cadmium body burden in cases of kidney damage. ${ }^{38}$

The ratio between kidney-Cd and liver-Cd was broadly consistent with the ratios between 3 and 8, derived from other studies of occupationally exposed people. ${ }^{27} 280^{33-35}$ (For these references we have calculated the ratios we have given from published values (arithmetic or geometric mean, or median) for the kidney cortex and liver.) For members of the general public, the ratio seems to be higher (11-39). ${ }^{30}{ }^{33-35}$ 41-43 Assuming a faster elimination of liver-Cd, the ratio would increase if the occupational exposure stopped. Also, it must be stressed that the calculated ratios from some of the studies of exposed workers mentioned were obtained for subject groups which contained a fraction of subjects with kidney dysfunction. Thus, for those subjects the kidney-Cd may have decreased faster than the liver-Cd. This will also tend to lower the ratio.

The subject with kidney-Cd of $355 \mu \mathrm{g} / \mathrm{g}$, but without signs of kidney dysfunction retired three years before this study but his B-Cd and U-Cd were still among the highest in the group. The combination of a very high kidney-Cd and a normal kidney function has been reported by others. ${ }^{27}{ }^{31}{ }^{32} \mathrm{~A}$ hypothesis is that there is a proportion of people who are resistant to renal dysfunction induced by cadmium, and others are more sensitive. ${ }^{44}$

The B-Cd and U-Cd are influenced by the current and past exposure. Part of B-Cd reflects the body burden, but a substantial part is related to the exposure during the past few months. ${ }^{39} 45$ Our results confirm previous findings ${ }^{46}$ that current concentrations of B-Cd may be used to estimate the BB-Cd. The correlation coefficient is equal to the one presented by Roels $e t a l^{7}$ in a subgroup of workers with normal kidney function. The correlations between $\mathrm{U}-\mathrm{Cd}$, on one hand, and kidney-Cd or liver-Cd, on the other, imply that $\mathrm{U}-\mathrm{Cd}$ reflects the BB-Cd after long term exposure, if no tubular damage has occurred. This is consistent with earlier published results. ${ }^{24} 274$ Two earlier Swedish studies ${ }^{10}{ }^{11}$ showed no correlation between U-Cd and kidney-Cd. This might be caused by the fact that in those studies most workers (17 of 20) were currently exposed, whereas in the present study about half of the subjects were retired and the rest had had relatively low exposure during later years of work.

No correlations could be found between the estimated CumAir-Cd and the measured kidney-Cd and liver-Cd. This may partly be explained by the uncertainties in the estimated and measured variables. Thus, we have not yet been able to validate the total cadmium exposure as estimated by air cadmium concentrations and expressed as CumAir-Cd by means of concentrations of cadmium measured in vivo. Even if the individual CumAir-Cd values had been accurately measured, they are not 
expected to be totally predictive of the cadmium intake, as this is influenced also by oral intake and respiratory function.

The BB-Cd values ranged up to $240 \mathrm{mg}$, and the mean was $50 \mathrm{mg}$. This is eight times higher than the value reported for occupationally unexposed Swedes. ${ }^{24}$ However, for highly exposed workers the mean can be up to 200 mg. ${ }^{2731333436}$

The figures used for calculation of the BB-Cd can be questioned. The data of Nordberg $e t a l^{24}$ stated that the fractions of the BB-Cd from the kidneys and the livers are about $50 \%-56 \%$ and $14 \%-18 \%$, respectively. It was also reported that a greater proportion of the BB-Cd comes from the liver at higher exposures. On the other hand, a Japanese study of occupationally unexposed subjects ended up with corresponding figures of $36 \%$ and $26 \%{ }^{47}$ Thus, a reasonable estimate for toxicological evaluations has been proposed, that one third of the BB-Cd is in the two kidneys. ${ }^{24}$

As already mentioned the variation in the kidney weight can be considerable. Moreover, the $80 \%$ range for the liver weight of middle aged men has been estimated to be 1500-2300 g. ${ }^{23}$ Animal experiments on liver tissue suggested that there might be a somewhat higher accumulation of cadmium in the periphery of the liver lobes. ${ }^{24}$ There is also an associated uncertainty as, generally, not all of the cadmium content of body organs is measured in necropsy studies. Thus, the variation in these variables and the uncertainty in the $x$ ray fluorescence measurement are responsible for the differences found in the body burden estimated from the kidney-Cd and liver-Cd, separately.

The B-Cd, U-Cd, and kidney-Cd were not different between subjects with and without kidney dysfunction. On the other hand, liver-Cd was higher for people with $\beta_{2}$ microglobulinuria. This indicates that liver-Cd can remain at a high value in cases with kidney damage. The same result was found when another commonly used cut off point for $\mathrm{U}-\beta_{2}-\mathrm{m}(34 \mu \mathrm{g} / \mathrm{mmol}$ creatinine) was used.

Table 2 also indicates a relation between the liver-Cd and the prevalence of $\beta_{2}$ microglobulin in the urine. Roels et $a l^{7}$ and Ellis et $a l^{11}$ showed that whenever a person's liver-Cd exceeded 30-40 $\mu \mathrm{g} / \mathrm{g}$ and CumAir-Cd $400-500 \mu \mathrm{g} / \mathrm{m}^{3} . \mathrm{y}$, there was evidence of kidney dysfunction. Our material contains only one subject with such a high liver-Cd value, and he did have renal damage.

In conclusion, the $x$ ray fluorescence turned out to be practically useful for measurements of liver-Cd. The U-Cd could be used to predict both liver-Cd and kidney-Cd. The relation between the kidney-Cd and the liver-Cd was in keeping with the non-linear shape found by others. However, in vivo measurements of kidney-Cd and liver-Cd did not correlate with the cadmium exposure estimates obtained as CumAir-Cd.

This study was supported by grants from the Swedish Council for Work Life Research. Dr Gunnar Spång, at the Compan Health Care Unit, Oskarshamn, Sweden is gratefully acknowedged for his valuable assistance with recruiting the subjects, and for sharing his personal knowledge about the work environ- ment at the battery factory. Mikael Lindén and Sven Brink, Department of Radiation Physics, Malmö are acknowledged for valuable discussion on spectrum analysis and for technical assistance during the study, respectively.

1 Friberg L, Elinder CG, Kjellström T, Nordberg GF, eds Cadmium and health: a toxicological and epidemiological appraisal. Vol I. Exposure, dose and metabolism. Boca Raton FL: CRC Press, 1985:103-78.

2 Chettle DR, Armstrong R, Todd AC, Franklin DM, Scott MC, Somervaille LJ. Measurements of trace elements in vivo. In: Yasumura S, Harrison JE, McNeill KG, Woodhead $\mathrm{AD}$, Dilmanian FA, eds. Advances in in vivo body composition studies. New York: Plenum Press, 1990:247-57.

3 Börjesson J, Mattsson S. Toxicology; in vivo $x$ ray forjesson J, Mattsson S. Toxicology; in vivo $x$ ray fluorescence for the assessment of heavy metal
tions in man. Appl Radiat Isot 1995;46:571-6

4 Nilsson U. Quantitative in vivo elemental analysis using $x$ ray fluorescence and photon scattering techniques. Applications to cadmium and lead in occupational and environmental medicine [thesis]. Malmö, Sweden: Department of Radiation Physics, Lund University, 1994.

5 Järup L, Elinder CG. Dose-response relations between urinary cadmium and tubular proteinuria in cadmiumexposed workers. Am f Ind Med 1994;26:759-69.

6 Adamsson E, Piscator M, Nogawa K. Pulmonary and gastrointestinal exposure to cadmium oxide dust in battery factory. Environ Health Perspect 1979;28:219-22.

7 Järup L, Elinder CG, Spång G. Cumulative blood-cadmium and tubular proteinuria: a dose-response relationship. In Arch Occup Environ Health 1988;60:223-9.

8 Langworth S, Elinder CG, Sundquist KG, Vesterberg O. Renal and immunological effects of occupational exposure to mercury. $\mathrm{Br} \mathcal{F}$ Ind Med 1992;49:394-401.

9 Ahlgren L, Mattsson S. Cadmium in man measured in vivo by $x$ ray fluorescence. Phys Med Biol 1981;26:192-6.

10 Christoffersson J-O, Mattsson S. Polarised $x$ ray in XRF analysis for improved in vivo detectability of cadmium in man. Phys Med Biol 1983;28:1135-44.

11 Christoffersson J-O, Welinder H, Spång G, Mattsson S Skerfving S. Cadmium concentration in the kidney cortex of occupationally exposed workers measured in vivo usin $x$ ray fluorescence analysis. Environ Res 1987;42:488-99.

12 Nilsson U, Ahlgren L, Christoffersson J-O, Mattsson S. Further improvements of XRF analysis of cadmium in vivo. In: Yasumura S, Harrison JE, McNeill KG, Woodhead AD, Dilmanian FA, eds. Advances in in vivo body composition studies. New York: Plenum Press, 1990:297-301.

13 ICRU (International Commission on Radiation Units and Measurements). Measurement of low-level radioactivity. Washington, DC: ICRU, 1972. (Report No 22.)

14 Friberg L. Further investigations on chronic cadmium poisoning. A study on rabbits with radioactive cadmium Archives of Industrial Hygiene 1952;5:30-6.

15 Franklin DM, Chettle DR, Scott MC. Studies relating to the accuracy of in vivo measurements of liver and kidney cadmium. fournal of Radioanalytical and Nuclear Chemistry 1987;114:155-63.

16 Schwartz LH, Richaud J, Buffat L, Touboul E, Schlienger M. Kidney mobility during respiration. Radiother Oncol 1994;32:84-6.

17 Statistical package for the social sciences. Release 6.0 Chicago: SPSS, 1993

18 Maenhaut W, Raemdonck $H$. Accurate calibration of $\mathrm{Si}(\mathrm{Li})$ detector for PIXE analysis. Nuclear Instruments and Methods in Physics Research 1984;B1:123-36.

$19 \mathrm{He}$ T, Gardner RP, Verghese K. An improved $\mathrm{Si}(\mathrm{Li})$ detector response function. Nuclear Instruments and Methods in Physics Research 1990;A299:354-66.

20 Hood WG. Polynomial curve fitter. BYTE 1987;June:15560.

21 Böriesson J. Studies of cadmium, mercury and lead in man. The value of $x$ ray fluorescence measurements in vivo [thesis] value of $x$ ray fluorescence measurements in vivo [thesis]. Malmö, Sweden:

$22 \mathrm{Kim} \mathrm{R,} \mathrm{Aro} \mathrm{A,} \mathrm{Rotnitzky} \mathrm{A,} \mathrm{Amarasiriwardena} \mathrm{C,} \mathrm{Hu} \mathrm{H.} \mathrm{K}$ $x$ ray fluorescence measurements of bone lead concentration: the analysis of low-level data. Phys Med Biol 1995;40:1475-85.

23 International Commission on Radiological Protection. Report of the task group of reference man. Oxford: Pergamon Press, ICRP, 1975. (Report No 23.)

24 Nordberg GF, Kjellström T, Nordberg $M$. Kinetics and metabolism. In: Friberg L, Elinder C-G, Kjellström T, Nordberg GF, eds. Cadmium and health: $a$ toxicological and epidemiological appraisal. Vol I. Exposure, dose and metabolism. Boca Raton: CRC Press, 1985:103-78.

25 Nilsson U, Schütz A, Skerfving S, Mattsson S. Cadmium in kidneys in Swedes measured in vivo using $x$ ray kidneys in Swedes measured in vivo using $x$ ray
fluorescence analysis. Int Arch Occup Environ Health 1995; 67:405-11.

26 Harvey TC, Thomas BJ, McLellan JS, Fremlin JH. Measurement of liver-cadmium concentrations in patients and industrial workers by neutron-activation analysis. Lan cet 1975;1269-72.

27 Roels HA, Lauwerys RR, Buchet J-P, Bernard A, Chettle $\mathrm{DR}$, Harvey TC, Al-Haddad IK. In vivo measurements of liver and kidney cadmium in workers exposed to this metal its significance with respect to cadmium in blood and urine. Environ Res 1981;26:217-40. 
28 Webb MAH, Chettle DR, Al-Haddad IK, Downey SPMJ, Harvey TC. Measurement of cadmium in liver and kidney using in vivo techniques. Ann Occup Hyg 1982;25:33-7.

29 Gompertz D, Fletcher JG, Perkins J, Smith NJ, Chettle DR Mason $\mathrm{H}$, et al. Renal dysfunction in cadmium smelters: Mason $\mathrm{H}$, et al. Renal dysfunction in cadmium smelters.
relation to in-vivo liver and kidney cadmium concentrarelation to in-vivo liver and
tions. Lancet 1983;1185-7.

30 Ellis KJ, Yuen K, Yasumura S, Cohn SH. Dose-response analysis of cadmium in man: body burden $v$ kidney dysfunction. Environ Res 1984;33:216-26.

31 Ellis KJ, Cohn SH, Smith TJ. Cadmium inhalation exposure estimates: their significance with respect to kidney and liver cadmium burden. F Toxicol Environ Health 1985;15:17387.

32 Guthrie CIG, Franklin DM, Scott MC, Chettle DR, Mason HJ, Smith NJ, et al. A longitudinal survey of exposure to cadmium fume - preliminary findings from in vivo body cadmium fume - preliminary findings from in vivo body burden measurements. In: Ellis KJ, Yasumura S, Morgan WD, eds. In vivo body composition studies. London: The

33 Mason HJ, Davison AG, Wright AL, Guthrie CJG, Fayers $\mathrm{PM}$, Venables KM, et al. Relations between liver cadmium, cumulative exposure, and renal function in cadmium alloy workers. Br $\mathcal{f}$ Ind Med 1988;45:793-802.

34 Franklin DM, Guthrie CJG, Chettle DR, Scott MC, Mason HJ, Davison AG, Newman-Taylor AJ. In vivo neutron activation analysis of organ cadmium burdens. Referent levels in liver and kidney and the impact of smoking. Biol Trace Elem Res 1990;26-27:401-6.

35 Morgan WD, Ryde SIS, Jones SJ, Wyatt RM, Hainsworth IR, Cobbold SS, et al. In vivo measurements of cadmium and lead in occupationally-exposed workers and an urban population. Biol Trace Elem Res 1990;26-27:407-14.

36 Armstrong R, Chettle DR, Scott MC, Blindt M, Mason HJ Longitudinal studies of exposure to cadmium. $\mathrm{Br} \mathcal{F}$ Ind $\mathrm{Med}$ 1992;49:556-9.

37 Svartengren M, Elinder CG, Friberg L, Lind B. Distribution and concentration of cadmium in human kidney. Environ Res 1986;39:1-7.
38 Baddeley H, Thomas BJ, Thomas BW, Summers V. Liver cadmium concentrations in metal industry workers. $\mathrm{Br} \mathcal{F}$ Radiol 1983;56:449-51.

39 Järup L Rogenfält A, Elinder C-G. Nogawa K, Kjellström $\mathrm{T}$. Biological half-time of cadmium in the blood of workers after cessation of exposure. Scand $\mathcal{F}$ Work Environ Health 1983;9:327-31.

40 Friberg L, Elinder CG, Kjellström T, Nordberg GF. General summary and conclusions and some aspects of diagnosis and treatment of chronic cadmium poisoning. In: Friberg L, Elinder C-G, Kjellström T, Nordberg GF, eds. Cadmium and health: a toxicological and epidemiological appraisal. VI II. Effecith: a coxicological and epidemiological appraisal. Vol II.

41 Ellis KJ, Vartsky D, Zanzi I, Cohn SH, Yasumura S. Cadmium: in vivo measurement in smokers and nonsmokers. Science 1979;205:323-5.

42 Elinder C-G. Normal values for cadmium in human tissues, blood, and urine in different countries. In: Friberg $\mathrm{L}$ Elinder C-G, Kjellström T, Nordberg GF, eds. Cadmium and health: a toxicological and epidemiological appraisal. Vol I. Exposure, dose and metabolism. Boca Raton: CRC Exposure, dose and

43 SIVARG (Swansea in vivo analysis research group). Body burden following exposure to heavy metals. Swansea: Department of Medical Physics and Clinical Engineering, Singleton Hospital, May 1990. (Report WEP181/100/2.)

44 Chettle DR, Ellis KJ. Further scientific issues in determining an occupational standard for cadmium. $A m \mathcal{F}$ Ind Med 1992;22:117-24.

45 Lauwerys RR, Bernard AM, Roels HA, Buchet J-P Cadmium: exposure markers as predictors of nephrotoxic effects. Clin Chem 1994;40:1391-4.

46 Järup L, Elinder CG. Decreased glomerular filtration rate in solderers exposed to cadmium. Occup Environ Med 1995;52:818-22.

47 Sumino K, Hayakawa K, Shibata T, Kitamura S. Heavy metals in normal Japanese tissues. Arch Environ Health 1975;30:487-94.

\section{Rejected manuscripts}

From February 1994, authors whose submitted articles are rejected will be advised of the decision and one copy of the article, together with any reviewers' comments, will be returned to them. The fournal will destroy remaining copies of the article but correspondence and reviewers' comments will be kept. 